\section{COMETS $^{1}$}

FOR several months past I have anxiously considered how I could best discharge the honourable duty which has been intrusted to me this evening. I have to deliver an astronomical discourse, and to do my very utmost to make that discourse adequate to the subject, adequate to this large and cultivated audience, and adequate to the memorable occasion on which the British Association has first crossed the Atlantic Occan.

I propose to address you this evening on the subject of comets, but it will be readily understood that, of a subject so vast and so elaborate, only a slender proportion can be comprised within a single lecture. The first question to be decided was how to select from the vast mass of materials those which would be most suitable for our discussion this evening. To describe the natural history of comets with any approach to completeness would be a very tedious, indeed almost an endless, task. We must rather select those episodes in the history which have especially added to our knowledge, and enabled us to obtain a rational vicw of the whole subject. Does not I.ongfellow tell us how impossible it would have been for him to portray the fortunes of Evangeline throughout every detail? He has only disclosed to us the picturesque and eventful phascs of that history. May I be permitted to say that I desire to treat my subject in a similar manner, and while concentrating my attention on the really important matters I shall yet follow the wanderers' footsteps, "not through each devious path, each changeful ycar of existence."

In pursuance of this scheme I shall at a single blow lop off all the earlier parts of the history. 'The great primitive discoveries of the character of comets and of their movements must be entirely omitted. The splendid researches of Sir Isaac Newton, and the classical achievement of Halley, are among this class. They are no doubt familiar to every cultivated mind, for they belong to that wondrous alliance between mathematics and astronomy which imparts a thrill of pleasure to the generous intellect. They are not for our discussion to-night.

I shall only address you upon the more recent acquisitions to our knowledge of comets, and in order to give definitencss to our programme, I shall select a certain epoch not yet twenty years old, which is to bound our retrospect into time past. 'There is a special appropriateness in the choice of the year 1866 as a starting point for the modern history of comets. A very memorable occurrence in that year attracted universal attention, and threw much and quite unexpected light on the nature of comets. The review of the subject given in this lecture will extend from the year 1866 to the present time. But even in this restricted interval it will not be practicable for me to give anything like an exhaustive account of the different researches that have been made. Every astronomical journal teems with observations of comets. Every year brings us one, or two, or three, or more comets; organised efforts are made to observe these comets to the utmost, and each scason has its own harvest of discoveries. Amid this host of claimants for our attention we must wend our way this evening, glancing at some discoveries, according to others such notice as their inportance may merit, but reserving special attention for the three monumental achievements in the modern history of comets. These are, firstly, the determination of the connection between comets and shooting stars; secondly, the spectroscopic researches on comets; and thirdly, the investigations of the tails of comets. The first of these subjects must be for ever associated with the name of Professor Schiaparelli, the second with the name of Dr. Huggins, the third with the name of Professor Bredichin.

It was long ago remarked by Kepler, in language of splendid exaggeration, that there were as many comets in the heavens as there were fishes in the ocean. There are comets large and comets small, comets with one tail, comets with two tails, and comets without any tail at all. Comets appear at uncertain and irregular intervals, they are not confined to any special part of the heavens. $\Lambda$ comet may be first discovered in one constellation, and after a journey across the heavens it may sink to invisibility in any other constellation. A comet is sometimes only seen for days or for weeks, but sometimes it remains visible for months or even for years. The features of the comet itself are also in a course of incessant transformation during its visit. Its size and its shape are not constant. The interval of a few days, or sometimes of even a few hours, suffices to work wondrous changes in a body almost spiritual in its texture.

Amid all these elements of confusion where are we to seek for

I Lecture by Prof. R. S. Ball, Astronomer-Royal for Ireland, at the Montreal meeting of the British Association. the law and the order which really underlie the phenomena? There is law and there is order. Each one of the myriad comets pursues a definite high-road through space. It is in the province of the mathematician and the astronomer to ascertain by their joint labours what the path is for each comet. The astronomer directs his telescope to the comet, and he reads from the graduated circles attached to his telescope the precise point in the heavens where the comet is located. He repeats this observation a few nights later, he docs it a third time, and his work is done. All the mathematician absolutely requires is to know the place of the comet accurately on three nights. He will no doubt be glad to accept further observations; they will help to eliminate the errors inseparable from such labours; they will enable hin to obtain three places of the comet purged from all sources of uncertainty. The comet is then within his toils. IIc can detcrmine the route which the comet is pursuing. He can by his calculations follow the comet in its movements through the profundity of space far beyond the penetration of the tclescope. The telescope only watches the comet during a brief portion of its career, but the subtle eye of the mathematician seldom loses sight of a comct once detected. He watches it recede to its greatest distance; he knows when the comet begins to return; he sees how it gradually approaches the sun. $\mathrm{He}$ assigns the spot on the heavens where the comet is first to appcar, and he tells the day and sometimes even the hour when the telescope will welcome the wanderer's return.

It has long been known that the highway of each comet is one of those graceful curves known to geomelers as conic sections. The comets which appear only once sweep through our system in a curve which cannot be distinguished from a perfect parabola. The small but exceedingly interesting class of comets which return periodically revolve in the most beautiful of all curves-the ellipse. The supreme law of gravitation has ordained that the comets must follow a conic section whereof the sun lies at one of the foci. But subject to this impcrative restriction the orbit of a comet may have every degree of variety. $\Lambda$ comet may revolve in a path so small that it only requires three years to complete a revolution. Another comet moving in a much longer ellipse will require seventy-five years. There may be every intermediate gradation, and there are some cometary orbits so vast that the mighty journey cannot be accomplished in less than thousands of years, while there are others whose orbits stretch out to a distance so stupendous that we fail to follow them in their wanderings. The ellipses seem to be utterly interminable, and in the language of mathematics we say that the orbit is parabolic.

In order to enunciate the first of the great modern discoveries which we are to consider to-night, it is necessary to associate with cach comet a certain particular elliptic path lying in a particular plane with a particular position in that plane, and with a particular magnitude. The comet is, in fact, to be identified by its path as its only permanent characteristic, for, though the comets may exist in myriads, yet no two comets follow the same course through space : such a contingency is too remote to be worthy of serious contemplation; it is, in fact, infinitely improbable.

There is not, I believe, a greater surprise in the whole of modern astronomy than the discovery of a myriad of small bodies stealthily accompanying a comet in its mighty journey, and the surprise is all the greater when we consider that in another aspect we have been long familiar with these small bodies, and we have called them shooting stars or luminous meteors. It was Schiaparelli who first demonstrated, in 1866 , the wholly unlookedfor connection between the showers of shooting stars and the movements of comets.

Every one is familiar with the very beautiful spectacle of a shooting star, which is seen to flash into the air and vanish in a streak of splendour. These little bodies were long an enigma in astronomy, but they have gradually been subordinated to law and order. It has been found that the sun which controls the mighty Jupiter does not disdain to guide with equal care the tiny shooting stars, and their movements are now tolerably well known. The received doctrine about the shooting stars has stood the severest test known to science-that is, the test of fulfilled prediction. The first great prediction in this refined branch of astronomy was made about twenty years ago. It was foretolc that a splendid shower of shooting stars would occur on the night of November 12th, 1866. All the world knows how triumphantly this prediction was fulfilled.

If I may be permitted, I would wish to narrate in a few words my own experience of that ever-memorable night. The details of that majestic spectacle have been engraved on my memory. 
I have had the good fortune to see other striking astronomical phenomena. The first was the glorious comet of 1858 , the last was the transit of Venus in 1882 ; but I have no hesitation in saying that no phenomenon I have ever seen in the heavens, and no spectacle that I have ever witnessed on the earth, has impressed me so deeply and so profoundly as the great shower of shooting stars in 1866 .

I was at that time astronomer to the late Earl of Rosse, at Parsonstown, and in the autumn of the year I attended my first meeting of the British Association at Nottingham. Fron: the lips of my esteemed friend, Mr. James Glaisher, I learned that a great shooting star shower was to be anticipated on the I2th of November. The prediction could not be put forward with all the confidence that we have when the almanac foretells an eclipse. It was rather a venture, by which an important theory was to be put to a severe test.

On the ever-memorable night I was occupied as usual in observing nebulæ with the present Earl of Rosse at the great reflecting telescope. In the early part of the evening the sky was clear, and the night was dark; but no unusual phenomenon occurred until about ten o'clock. I was at that moment watching a nebula at the eye-piece, when I was startled by an exclamation from the assistant by my side. I looked up just in time to see a superb shooting star stream across the heavens. Soon came another star, and then another, and then in twos and in threes. We saw at once that the prediction was about to be verificd. We ceased the observations with the telescope and ascended to the top of the wall, which forms one of the supports of the great telescope. This position commanded an extensive view of the heavens, and from it Lord Rosse and myself, on a beautiful starlight night, witnessed that gorgeous display of celestial fireworks which has gi en fresh impetus to astronomy.

It was not merely the incredible number of the shooting stars that was remarkable. They came no doubt in thousands which no man could number, but what was especially to be noticed was the intrinsic brilliancy of each individual star. There were innumerable meteors that night any one of which would have elicited a note of admiration on any ordinary occasion. As the night wore on and the constellation of Leo climbed up from the east, then the display exhibited a very interesting and characteristic feature, for, as each shooting star was projected across the sky, the track which it followed was invariably directed from the constellation of Leo, nay, even from a particular point in that constellation. So marked a property of the shower suggests an appropriate name, and accordingly this particular group of shooting stars bears the not unpleasing name of the "Leonids."

It is easy to demonstrate that the apparent radiation of the meteors from a point is only the effect of perspective. They are really moving in parallel lines. Those parallel lines have a vanishing point, and that point is the radiant in the constellation of Leo. As we stood on the walls of the great telescope we saw the true character of the radiant most beautifully demonstrated. Those meteors which appeared close to the radiant pursued a track which was greatly foreshortened. A few that were actually at the radiant, or very close to it, had no visible track at all, they merely shone like a very rapidly variable star, which rose from invisibility to brilliancy, and then again declined to evanescence, all within the space of a very few seconds. In these exceptional cases we vicwed the track of the stars "end on." They were, in fact, coming straight at us, but fortunately there was a kindly screen which shielded the earth that night from the awful metcoric tempest. Each one of those meteors hurries along with a velocity truly appalling; it is more than a hundred times swifter than the swiftest bullet that was ever fired from a rifle. It is really the demoniacal impetuosity of this velocity which is the source of the earth's safety. The meteor moving freely through space suddenly plunges into our atmosphere. Instantly a gigantic resisting force is aroused. The velocity of the meteor is checked, and the energy stored in that velocity is transformed into heat. That heat is enough to raise the body red hot, to raise it white hot, nay, even to drive the solid mass into a streak of harmless vapour. Of all the countless myriads of shooting stars which went to their destruction on that night, not one single particle has ever been recovered. These facts, when placed in the crucible of the mathematician, conduct him to a solution of the problem as to the nature of the great shooting star shower. It is to be remembered that the law of gravitation determines the movements of these bodies. The meteor, ere its disastrous collision with our atmosphere, must have been traversing the solitudes of space in an elliptic path with the sun in one of the foci. This is as true of a meteor the size of a grain of sand as it is of the earth or the planet Jupiter. The astronomer then approaches the question with the knowledge that the orbit of the meteors is an ellipse (or at al: cvents one of the conic sections), but what the particular ellipse is must be decided by an appeal to the actual observations. The facts are simple enough: we note in the first place that the shower took place on the I2th of November, but on the 12th of November in each year, or on any other fixed date, the earth is always at a particular point of its annual journey round the sun. The stream of meteors must therefore pass through that particular point of space, and hence the search for the orbit is narrowed, for only ellipses which pass through this particular point can fulfil the conditions of the question. Another clue is afforded by the position of that point in Leo from which all the meteors scemed to radiate. The mathematician sees how to fit the ellipse so that it shall give the proper radiant. And now the question has been narrowed almost to the last point. One more appeal to observation and the ellipse will be absolutely known. All we must now learn is how long the swarm of meteors takes to complete the circuit of its mighty path. To answer this question profound historical research has been made by Prof. Newton, and a mathematical research has been made which has given additional lustre even to the name of Adams. The great showers of meteors have been shown to have occurred at intervals for the last $\mathbf{I}, 000$ years. The earliest record was in the year 902 , on the occasion of the death of the Moorish king Ibrahim-bin-A hmad. An old chronicler describes how the event was solemnised in the heavens no less than on the earth; he tells us how "that night there were seen as it were lances, an infinite number of stars which scattered themselves like rain to right and left, and that year was called the year of the stars." We now know that this exhibition was not, as the old chronicler thought, a miraculous compliment to the memory of the deceased prince, it was really only a showe: of the Leonids, such a shower as appears every thirty-three years, such a shower as appeared in 1866, such a shower as may be anticipated in the year $\mathbf{1} 899$.

By these researches the path followed by the Leonids has been completely determined. The plane of the ellipse, and every circumstance of its position, and its proportions have been reduced to numerical accuracy. The shoal of meteors pursue their path unseen by any astronomer, but the mathematician knows precisely where they are at this moment, and at every moment.

This point being gained a great discovery was made by Schiaparelli in 1866. A bout that time a comet was seen, this comet was duly observed, and the path which it followed was computed. There was nothing very remarkable about the comet, and it would not now be much remembered save for one most extra. ordinary circumstance which Schiaparelli was the first to proclaim. Like the shoal of meteors this comet also revolves in an elliptic path around the sun. This is a mere consequence of the law of gravitation and calls for no remark, but the fact that the two ellipses lie in the same plane is a very remarkable coincidence which could not be overlooked. When we further come to see that the two ellipses are of the same size and shape, when we sce that they are placed in the same position, when we see, in fact, that the ellipse which is the orbit of the shooting stars is identical with the orbit of the comet, then we have obtained a result which ranks as one of the most.striking astronomical discoveries that this century has witnessed.

The Leonids therefore travel through space precisely in the track of the comet of 1866 . The question at once arises of the relation of the shoal of meteors to the comet. Is the shoal of meteors one thing and the comet another thing, and do both these things happen to be travelling in the same orbit without any necessary connection, or are we to suppose that the two objects, if not actually identical, are at all events very intimately connected ? These are problems which, in the present state of our knowledge, it seems difficult to solve. I shall only lay down onc or two principles which may help us to form a conclusion.

Whatever be the nature of comets, or the materials of which they are composed ; whether they be faint or bright, large or small, periodic or parabolic; one fact is certain, their masses are all extremely small in comparison with their great dimensions. I shall indeed, at a later part of this lecture, show that comets seem to be almost imponderable when compared with the great masses of the sun and of the planets. The great bulk of a comet necessarily implies that many parts of it are at a considerable distance from its centre of mass. Hence for a double reason the 
coherence of the parts of a comet arising from their mutual gravitation is an extremely feeble force. Each particle of the comet is directly solicited by the sun to pursue a path of its own, and if the forces of coherence be not adequate to overcome this tendency the comct must undergo a gradual degradation into separate parts. As the periodic time of the orbit of each part will vary, it will follow that the comet will be spread out in fragments along its path. It would seem that these small fragments constitute the motcors.

It is often supposed that meteorites, or solid bodies which actually tumble down on the earth, are connected with shooting stars, and hence it has been asserted, and even by very good authority, that meteorites are connected with comets, if not actually parts of comets. I merely mention this view for the purpose of saying that to me it scems quitc unsupported by the facts. There is no reliable evidence, or indeed no evidence at all, that meteorites are connected with the periodic showers of shooting stars which alone are connected with the comets. This would not be the occasion to discuss the interesting question as to the origin of unctcorites, but all the available facts secm to me to point to an origin on some body far more closely resembling a planct than a comet.

It is now about sixteen years since Dr. Huggins first turned his spectroscope upon these bodies, and showed that certain lines in the spectra of the comet of 1868 were identical with certain of the lines of carbon. Since then many comets have been ubscrved and much valuable spectroscopic work has been done. This has been so often and so fully discussed that I do not now propose to dwcll on the subject at length. It is, however, quite impossible to avoid a brief reference to one of the latest efforts of Dr. Huggins' marvellous skill. He has succeeded in inducing a comet to depict with absolute fidelity its spectrum on the photographic plate. That photograph has not only shown the lines which coutd be seen with the spectroscope, but it has also exhibited many other lines in the invisible part of the spectrum. The discussion of this photograph and of the bright lines and the dark lines it contains is full of interest, though here I shall only remark that it contains convincing cvidencc of the presence of carbon in this comet.

That a comet's tail should be directed away from the sun is a very remarkable and characteristic feature of this group of bodies. At the first glance it seems at variance with every reccived doctrine of astronomy. The great law of Nature which regulates the movements of the heav nly bodies is the law of attraction. The very movement of a comet in an elliptic path around the sun is in itself a demonstration that the comet is attracted by the sun.

While the comet as a whole is amenable to the law of gravitation, it is obvious that the materials, whatever they may be, which constitute the tail of the comet must be repelled by some force of an exceptional character. This force must sometimes be of very great intensity. Cases are not wanting where a comet, after darting in close to the sun, has actually whirled round the sun with the stupendous velocity of 300 miles a second, and in a few hours has commenced its outward journey. During this appalling swoop what has been the conduct of the tail of the comet? It seems necessary to believe that at the commencement the tail was streaming away for millions of milcs on one sile of the sun, while in a few hours the tail has gone completely round, so as to be extending for millions of miles in the opposite direction. No known laws of mechanics allow us to believe that the same tail is seen under circumstances so diverse. We are compelled to believe that the tail is constantly dissipated and constantly renewed. It would, in fact, seem that the tail of a comet was in some respects like the column of smoke ascending from a chimney - the column remains, but the particles of which that column consists are in perpetual transition.

In the study of this subject we have to make use of the interesting labours of Prof. Bredichin of Moscow. This accomplished astronomer has devoted himself for many years to the collection and to the discussion of all the known phenomena of comets' tails, and he has succeeded, I believe, in taking a considerable step in the solution of the problems involved. In the first place he has shown that there are different types of comets, and he has proceeded to classify them. There are, first of all, the comets with very long and very straight tails, such, for instance, as the comet of 1874 , and many others. The next class included the tails of a scimitar shape. These are often of very great splendour, though not so long or so straight as those of the first type. The great comet of $185^{8}$ may be cited as an illustration of this class. The third and last class of comets' tails are very short and curved. It is to be observed that these tails sometimes exist in combination, so that a comet is often decorated with two tails of different types.

Once the form of the tail has been laid down, and the perihelion distance of the comet given, then the investigation of the forces adequate to the production of that tail is a problem admitting of numerical solution. It can be demonstrated that the straightest tail that ever strcamed from a comet could be produced by a repulsive force not more than twelve times as great as the intensity of gravitation at the same distance. This number twelve will be the characteristic of tails of the first type. The tails of the second type vary within certain limits, but speaking generally, the repulsive force adequate to their production need not be more than abont equal to the force of gravitation itself. The tails of the third type would be explained if the repulsive force were only the fifth part of gravity.

The next question that arises is as to the physical explanation of the repulsive force which produces these tails. We have to find this force of three different intensities, one about twelve times as great as gravity, one about equal to gravity, and one about a fifth of gravity. Before wc postulate the cxistence of a new force of some unknown character, it is surely our duty to inquire whether there may not be some force already known which is competent to produce the phenomena. The best known repulsive force is of course that with which every one is familiar in connection with electricity. Flectricity attracts electricity of an opposite typc, while it repels that of the same type. We are also aware that in some mystcrious manner the sun is connected with electricity. We know that the phenomena of terrestrial magnetism are connected with solar phenomena, and hence we are tempted to inquire whether the electricity of the sun may not offer an adequate explanation of the phenomenon of the comet's tail.

Let us suppose that the sun is attracting a distant body by virtue of gravitation, and at the same time repelling that body in virtue of the fact that the sun and the body are both charged with electricity of the same name. When the attracted body is one of large dimensions, the attraction will vastly exceed the repulsion, and indeed the lattcr may be cntirely neglected in most cases. There is, howcver, a radical difference between the nature of the electrical forces and the nature of the gravitational forces. The latter are proportional to the masses of the attracting bodies, while the electrical forces are proportional to their surfaces. The mass varies as the cube of the linear measurements, while the surface only varies as the square. The relative efficiency of the electric repulsion in comparison with the gravitational attraction increases as the radius of the particle decreases. It must thus necessarily follow that no matter how great may be the preponderance of the power of gravitation on masses of finite dimensions, yet it must always be possible, other things being equal, to have a particle so small that the electrical repulsion shall excced in any required ratio the intensity of the attraction of gravitation.

As the comet draws near the sun, the heat it experiences increases, so that the materials of the comet begin to dilate, and to be driven off into a vaporous condition. The matter is thus resolved into a state of extreme subdivision. These separate particles are charged with an electricity similar to that of the sun, and in virtue of their minuteness the intensity of that repulsion has become sufficient to sweep off the particles in a stream, and thus generate the tail.

Such is the modern view of the formation of comets' tails. Professor Bredichin has given good reasons for thinking that we can even riscover the special ingredients which enter into the formation of each of the three types of tail. It seems, from the molccular nature of hydrogen, that this element is especially suitable for the tails of the first type. The tails of the second type seem to arise from some substances possessing the properties of hydrocarbons, while the tails of the third type contain some elements which seem to have a high atomic weight. The theory of Professor Bredichin is well illustrated by the comet of 1858 . This comet, besides the majestic curved tail, the object of so much admiration, had a pair of long, faint, slender tails, streaming straight from the head. These two objects were doubtless the edges of a conical tail of the first type, too faint to be visible throughout its entire extent. The great tail was one of the second type.

We have many reasons for belicving that the masses of comcts are very much less than the masses of the planets. We 
might indeed almost conclude that the masses of the comets are inappreciable. Let us briefly indicate the grounds for this important conclusion.

The sun and the planets form a system characterised by perfect order and symmetry. We have the sun in the centre. We have all the great planets moving round the sun in the same direction. They all move nearly in circles, and all these circles lie nearly in the same plane. This organisation is a necessary modus vivendi among the bodies of our system. Each planet acts and reacts upon all the other planets, but, owing to the circumstances of their movements, their irregularities are but small, and the permanence of the system is insured. Alter that system to any extent, merely reverse for example the direction in which one of the planets is moving, and the whole compromise is destroyed. The actions and reactions, instead of being quickly balanced, will go on accumulating, and the seeds of confusion and ultimate dissolution have been sown. But we have in our system thousands of comets which repudiate all the regulations by which the planetary convention is restrained. Comets come in what direction they please, they move; in every plane but the right one, and their orbits are not in the least like circles. The very fact that our earth continues to revolve around the sun so as to be a fit abode for life, is a proof that comets cannot have any considerable mass. If comets had mass then organic disease would be introduced into the solar system which must ultimately prove fatal.

Science has gradually dissipated the fears which once invested comets : they are interesting and beautiful visitors which come to please and to instruct, never to threaten or to destroy.

\section{NOTES}

THE autumn Congress of the Sanitary Institute of Great Britain will be held this year at Dublin, and the programme of the proceedings has been issued. The President of the Congress is Sir Robert Rawlinson, C. B., who will open the Congress with an inaugural address on Tuesday the 30 th inst., and the proceedings will last until October 4. The Congress is divided into three sections-the first, "Sanitary Science and Preventive Medicine"; the second, "Engineering and Architecture" ; and the third, "Chemistry, Meteorology, and Geology." Of the first section, the president is the Registrar-General for Ireland, Mr. Thomas W. Grimshaw, M.A., M.D. In the section of "Engineering and Architecture," the president is the Engineering Inspector of the Local Government Board for Ireland, Mr. C. D. Cotton, C.E. ; and the president of the section of "Chemistry, Meteorology, and Geology" is Mr. C. A. Cameron, M.D., the City Analyst and Superintendent Medical Officer of Health for Dublin. The sectional meetings and the general meetings will be held at Trinity College, where the opening address will be delivered on Tuesday evening by Sir Robert Rawlinson. On Wednesday morning the actual work of the Congress will commence with the address of the president of the first section, and the remainder of the day will be taken up with the reading of papers and their discussion, while a conversazione will be held in the evening. The business of the second section will be taken on Thursday, October 2, and in the evening a lecture will be delivered to the Congress by Dr. Alfred Carpenter on "Education by Proverb in Sanitary Work." On Friday, after the third section, the closing general meeting of the Congress will be held. Arrangements for excursions will be made for the Saturday.

THE fifth International Congress of Hygiene, which has concluded its session at the IIague, is reported to have been highly successful ; it was decided to accept the invitation from Vienna for $\mathbf{x} 886$.

I $\mathrm{T}$ is reported that Mr. Melville, chief engineer of the Jeannette Ixperlition, will command a Polar expedition which it is said will start next autumn to attempt to reach the Pole viâ Franz Josef Land. It is stated that Mr. Cyrus Field and the New York Yacht Club will each furnish one-half the cost of the expedition.
In the course of the present month a geographical professorship will be established at each of the Russian universities. In Germany, fourteen out of twenty-one universitics have a chair of this sort.

A VERY favourable Report has been issued of the second year of the College Hall of Residence for Women Students. That such an institution was wanted is shown by the fact that last autumn another house had to be added in order to meet the number of applications from students. The Hall is already almost self-supporting, and in another year will probably be entirely so ; and it is hoped that this will encourage friends to assist the Committee in paying off the Ioool. they had to borrow in order to extend the premises. Subscriptions and donations may be sent to Mrs. Edward H. Busk, 44, Gordon Square, W.C.

THE Geographical Society have received a letter from Mr. H. H. Johnston, who has been sent out to explore and collect plants on Mount Kilimanjaro. It is dated June 18 , from "Uvura, in Chagga, altitude 5000 feet." "For nearly a week now,' Mr. Johnston says, "I have been settled on Kilimanjaro, camped on one of the loveliest sites in the world. Above me towers into the deep blue heaven the snowy head of Kibó, around me are green hills and forest-clad ravines in whose profound depths great cascades of water leap from rock to rock and splash the fronds of luxuriant ferns; before me lies spread out a vast blue plain--'all the world,' as my host, the chief Mandara, proudly says, and my view southward is only bounded by the distant horizon. Perched as I am up here on the shoulder of a great buttress of the mountain, I seem to be on a level with the uppermost flight of the vultures, who hardly ever soar higher, and who poise themselves and wheel in circles over the awful depths at my feet. When the first cares of my installation are over, I am going to set to work on a picture such as I see before me, and call the view "à vol de vautour." "

THE difference between the temperatures of places in America and those of places in similar latitudes in Europe is already well known, but it would hardly be expectel to be so great as it actually was in January of this year. That month was a mild one all over Europe, but in the United States, especially in the eastern part, it was extremely cold. Thus, in Nashville and Knoxville, in the same latitude as Malta, the thermometer marked $26^{\circ} .7 \mathrm{C}$. and $23^{\circ} \cdot 3 \mathrm{C}$. of cold, while in Malta it was only $5^{\circ} .9$ below zero. At Indianapolis and Columbus it was $3 \mathrm{r}^{\circ} \cdot 7 \mathrm{C}$. and $28^{\circ} \cdot 9 \mathrm{C}$. respectively below zero, while at Madrid, in the same latitude, the maximum was $9^{\circ}$ below zero. The average temperature of the month in the States was $3^{\circ} \mathrm{C}$. to. $5^{\circ} \mathrm{C}$. beyond the normal average.

THE experiment of MM. Renard and Krebs in balloon steering at Meudon, of which so much has recently been heard, formed the subject of a paper read before the Academy of Sciences on the 18 th ultimo. The solution of the problem of aërial navigation was first attempted in 1855 by M. Giffard, who employed steam, then in 1872 by $M$. de Lôme, and finally by M. Tissandier, who was the first to apply electricity. The conditions which MM. Renard and Krebs studied to fulfil were. steadiness of the path obtained by the shape of the balloon, and the arrangement of the rudder; the diminution of resistance while travelling by the proportion of the dimensions-bringing together the centres of traction and resistance; and finally, to attain a speed capable of resisting the winds prevailing in France during the greater part of the year. The paper then enters into details of the construction, and of the journey, during which the writers claim they were able to manœuvre the balloon as easily. and effectively as a ship is put through its evolutions.

WE have recently received from various scientific societies in the United States their late publications. The contents of thesc 